\title{
Safety of apatinib plus S-1 for advanced solid tumor as palliative treatment
}

\author{
SIYING CHEN ${ }^{1}$, JIFENG SUN $^{1}$, LUJUN ZHAO ${ }^{1}$, YUNGUANG SUN $^{2}$, DAN JIA ${ }^{3}$, \\ YONGCHUN SONG ${ }^{1}$, JING LUO $^{1}$, HAILONG LEI $^{4}$ and NINGBO LIU ${ }^{1}$
}

\author{
${ }^{1}$ Department of Radiation Oncology, Tianjin Medical University Cancer Institute and Hospital, National Clinical \\ Research Center for Cancer/Key Laboratory of Cancer Prevention and Therapy, Tianjin Clinical Research Center for Cancer, \\ Tianjin 300060, P.R. China; ${ }^{2}$ Department of Pathology, Medical College of Wisconsin Cancer Center, Milwaukee, WI 53226, \\ USA; ${ }^{3}$ Department of Radiation Oncology, The First Hospital of Jilin University, Changchun, Jilin 130000; \\ ${ }^{4}$ Department of Radiation Oncology, The People's Hospital of Wuhai Inner Mongolia, \\ Wuhai, Inner Mongolia 016000, P.R. China
}

Received October 31, 2019; Accepted July 7, 2020

DOI: 10.3892/etm.2020.9494

\begin{abstract}
The aim of the present study was to explore the safety of apatinib plus S-1 in treating advanced solid tumors after failure of two or more lines of chemotherapy. A total of 33 patients with advanced cancer treated between April 2016 to March 2019 were retrospectively analyzed. Of these, 13 patients had non-small cell lung cancer (NSCLC), 13 patients had SCLC, 4 patients had esophageal cancer and 3 had cervical cancer. All patients were treated with apatinib $250 \mathrm{mg}$ once daily combined with S-1 $60 \mathrm{mg} / \mathrm{m}^{2}$ twice daily for 14 days, repeated every 3 weeks. Adverse reactions were observed until aggravation of adverse reactions beyond the tolerable range or disease progression, and the survival rate and clinical benefits were calculated. The results suggested that the incidence rate of adverse effects (grade 3-4) was $45.5 \%$ $(15 / 33)$. The top three severe adverse effects were hypertension $(15.2 \%)$, thrombocytopenia $(12.1 \%)$ and proteinuria $(9.1 \%)$. A total of 2 patients with lung squamous-cell carcinomas died of severe pulmonary hemorrhage. Other adverse reactions were tolerated in the cohort. A total of 10 patients achieved partial response and the objective response rate was $30.3 \%$. Furthermore, 13 patients achieved stable disease and 10 patients had progressive disease, and accordingly, the disease control rate was $72.7 \%$. In conclusion, apatinib plus S-1
\end{abstract}

Correspondence to: Professor Ningbo Liu, Department of Radiation Oncology, Tianjin Medical University Cancer Institute and Hospital, National Clinical Research Center for Cancer/Key Laboratory of Cancer Prevention and Therapy, Tianjin Clinical Research Center for Cancer, 8 Huanhu West Street, Tianjin 300060, P.R. China

E-mail: liuningbo@tjmuch.com

Key words: apatinib, advanced solid tumor, safety, adverse reactions for advanced solid tumor patients as palliative treatment have a certain efficacy and was relatively safe but should be used with caution in patients with squamous-cell lung carcinoma and the efficacy and safety requires further assessment.

\section{Introduction}

An estimated 4,292,000 new solid tumor cases and 2814,000 solid tumor-associated deaths were reported in China in 2015 (1). In general, surgery is the most efficient therapy for early-stage tumors, but most of the patients experience relapse after radical surgery (2). Furthermore, targeted therapy and immunotherapy are suitable for specific populations and certain patients may develop drug resistance after treatment. Multi-line chemotherapy and local radiotherapy are recommended as salvage treatments for these recurrent and refractory tumors and no alternative treatment is available for these patients, but they may respond to salvage treatment (3).

Tumor cells require nutrients to support proliferation, growth and metastasis, which causes abundant new blood vessels to develop (4). Aberrant angiogenesis is considered to be the key feature of tumorigenesis, and therefore, tumor growth may be suppressed by blocking this process (5). The vascular endothelial growth factor (VEGF) pathway is crucial in angiogenesis, with VEGF receptor-2 (VEGFR-2) being the leading signaling receptor involved in this pathway $(6,7)$. Apatinib, a small-molecule inhibitor of VEGFR-2, is an orally bioavailable agent that is currently being studied in multiple tumor types. It may significantly inhibit angiogenesis of tumors and was proven to be well-tolerated, safe and effective in the clinic (8). Apatinib has shown favorable results in gastric cancer, breast cancer, lung cancer and esophageal cancer in Phase I/II/III trials, with secondary hypertension, hand-foot syndrome, fatigue and positive urine protein being the most frequent treatment-associated adverse events (9-17). S-1(Tegafur Gimeracil Oteracil Potassium Capsule) is a combination of novel oral fluoropyrimidine-based agents, exhibiting potent antitumor activity and low gastrointestinal 
toxicity (18). Monotherapy with S-1 has provided a high degree of relief for patients with various types of advanced tumor (19). In fact, $>90 \%$ of patients with malignant tumors succumb due to multidrug resistance (MDR) (20,21). Apatinib is able to reverse MDR by inhibiting ATP binding cassette transporters (22). Thus, apatinib combined with traditional chemotherapy drugs may achieve effective results and protect against the emergence of MDR. Therefore, the safety and efficacy of apatinib combined with S-1 in patients with advanced cancer were explored in the present study.

\section{Materials and methods}

Patient eligibility. From April 2016 to March 2019, patients with advanced cancer who failed two or more lines of chemotherapy and were then treated with apatinib combined with S-1 at Tianjin Medical University Cancer Hospital (Tianjin, China) were retrospectively evaluated. The key inclusion criteria were as follows: i) Patients with malignant tumors, age $\geq 18$ years; ii) patients who had received second-line treatment (radiotherapy or chemotherapy), and were refractory or had relapsed iii) at least one measurable lesion; iv) Karnofsky performance status (KPS) $\geq 80$ at enrollment; v) failed to tolerate another chemotherapy; vi) took the combination of apatinib and S-1 for at least one cycle. All patients provided written informed consent and the present study was approved by the Ethics Committee of Tianjin Medical University Cancer Hospital (Tianjin, China). The trial is registered at ClinicalTrials.gov (no. NCT04128800).

Treatment methods. All patients received oral apatinib $250 \mathrm{mg}$ once plus S-1 $60 \mathrm{mg} / \mathrm{m}^{2}$ twice daily on days 1-14, repeated every 3 weeks. The examination of hematological, liver and kidney function, urinalysis, tumor markers and electrocardiogram were routinely performed during treatment with apatinib plus S-1 and all patients had a reassessment after every treatment cycle. The color ultrasound of the upper abdomen and neck lymph nodes, bone scan, enhanced CT of the chest and MRI of the brain were performed every two cycles. In the meantime, adverse reactions of patients were recorded in detail, including myelosuppression, nausea and vomiting, hand-foot syndrome (HFS), fatigue, proteinuria and hypertension, prior to and after each taking the drug cycle. During treatment, if a patient experienced grade 3 or 4 neutropenia or thrombocytopenia, recombinant human granulocyte colony-stimulating factor or interleukin-11 was administered by subcutaneous injection. Treatment was continued until disease progression or the occurrence of intolerable adverse effects. Of note, patients with a bleeding tendency were closely monitored.

Outcome assessments. Complete response (CR), partial response (PR), progressive disease (PD) and stable disease (SD) were defined according to the Response Evaluation Criteria in Solid Tumors 1.1 (RECIST guideline version 1.1). The objective response rate (ORR) was defined as $\mathrm{ORR}=\mathrm{CR}+\mathrm{PR}$ rates. The disease control rate (DCR) was defined as $\mathrm{DCR}=\mathrm{CR}+\mathrm{PR}+\mathrm{SD}$ rates. Toxic reactions were assessed in accordance with the National Cancer Institute-Common Toxicity Criteria for Adverse Events version 4.0 (NCI-CTCAE guideline version 4.0).
Progression-free survival (PFS) time was defined as the time from the first day of each treatment cycle to the first found evidence of PD on imaging. Overall survival (OS) time was defined as the time from the first day of each treatment cycle to the time-point of death or the last follow-up of patients.

Statistical analysis. SPSS version 24.0 (IBM Corp.) was used for statistical analysis. Only patients who received at least one cycle of treatment were included in the analysis. The association between the patients' characteristics and curative effects was analyzed using the $\chi^{2}$ test. The association between clinical characteristics and severe adverse effects was also analyzed using the $\chi^{2}$ test. Survival analysis was performed using the Kaplan-Meier method by log-rank test. $\mathrm{P}<0.05$ was considered to indicate a statistically significant difference.

\section{Results}

Patient characteristics. A total of 33 patients were enrolled in the present study. Their baseline characteristics are summarized in Table I. Among them, 22 patients were male and 11 were female with a median age of 60 years (range, 40-77 years). There were $13(41.9 \%)$ patients with NSCLC and also $13(41.9 \%)$ patients with SCLC. The NSCLC patients included 7 patients $(21.2 \%)$ with adenocarcinomas and 6 (18.2\%) with squamous-cell carcinomas; furthermore, there were 3 patients $(9.1 \%)$ with cervical cancer and 4 patients $(12.1 \%)$ with esophageal cancer. Prior to receiving their treatment as part of the present study, 32 patients $(97.0 \%)$ had received palliative chemotherapy, $26(78.8 \%)$ had received radiotherapy, $12(36.4 \%)$ had received concurrent chemoradiotherapy and only 2 patients $(6.1 \%)$ had undergone surgery. A total of 114 cycles of treatment were recorded, with a median of 3 cycles per patient (range, 1-6 cycles). The characteristics of the patients in the concurrent chemo-radiotherapy group are presented in Table SI.

Adverse effects. As presented in Table II, the most common treatment-associated toxic effects and adverse events were anemia (23.7\%), hypertension (22.8\%), leukopenia (19.3\%), increase of bilirubin (15.0\%) and proteinuria (13.0\%). These side effects were of grade 1-2 and were tolerable and controllable. However, the incidence of other side effects, including thrombocytopenia, nausea, HFS, hemorrhagic tendency and diarrhea, were low. As presented in Table III, all of the 33 patients had experienced toxicities and side effects and 15 of them had severe adverse effects (grade 3-4) with an incidence rate of $45.5 \%$. The top three severe adverse effects (grade 3-4) were hypertension (15.2\%), thrombocytopenia $(12.1 \%)$ and proteinuria $(9.1 \%)$. As presented in Table IV, there was no significant association with age, gender, KPS score, treatment cycles and cancer type. A total of 5 patients discontinued treatment after cycle 1, which was due to disease progression in 3 cases and due to unknown reasons in 2 cases. Furthermore, 5 patients discontinued treatment after two cycles, which was due to personal will in 3 cases, due to cerebral embolism in 1 case and due to radiation pneumonia in 1 case. The treatment-associated toxicities and side effects in all these patients were mild and manageable. 
Table I. Characteristics of patients $(n=33)$.

\begin{tabular}{|c|c|}
\hline Characteristics & Value \\
\hline Age (years) & $60(40-77)$ \\
\hline \multicolumn{2}{|l|}{ Sex } \\
\hline Male & $22(66.7)$ \\
\hline Female & $11(33.3)$ \\
\hline \multicolumn{2}{|l|}{ KPS score } \\
\hline 80 & $25(75.8)$ \\
\hline 90 & $8(24.2)$ \\
\hline 100 & 0 \\
\hline \multicolumn{2}{|l|}{ Cancer type } \\
\hline Lung squamous cell carcinomas & $6(18.2)$ \\
\hline Lung adenocarcinoma & $7(21.2)$ \\
\hline Small cell lung cancer & $13(39.4)$ \\
\hline Esophageal cancer & $4(12.1)$ \\
\hline Cervical cancer & $3(9.1)$ \\
\hline \multicolumn{2}{|l|}{ Previous treatment received } \\
\hline Surgery & $2(6.1)$ \\
\hline Radiotherapy & $26(78.8)$ \\
\hline Chemotherapy & $32(97.0)$ \\
\hline Concurrent chemoradiotherapy & $12(36.4)$ \\
\hline \multicolumn{2}{|l|}{ Treatment during medication } \\
\hline Primary tumor radiotherapy & 0 \\
\hline Metastasis radiotherapy & $4(12.1)$ \\
\hline \multicolumn{2}{|l|}{ Cycles (apatinib + S-1) } \\
\hline 1 & $5(15.2)$ \\
\hline 2 & $5(15.2)$ \\
\hline 3 & $1(33.3)$ \\
\hline 4 & $2(6.1)$ \\
\hline 5 & $2(6.1)$ \\
\hline 6 & $8(24.2)$ \\
\hline Average & 3 \\
\hline
\end{tabular}

Values are expressed as n (\%) or median (range). KPS, Karnofsky performance status.

A total of 2 deaths $(6.1 \%)$ were recorded during the treatment. These 2 patients with lung squamous-cell carcinomas died of massive hemorrhage instead of disease progression after four and two cycles of treatment, respectively. Both of these were treatment-associated deaths.

Therapeutic outcomes and survival analyses. Until March 01, 2019, 22 of the patients of the present study had died and 11 survived. The disease had progressed in 9 cases and 24 had no disease progression. No CR was achieved and 10 patients achieved PR, resulting in an ORR of $30.30 \%$. Furthermore, 14 patients achieved SD and 9 patients had PD, resulting in a DCR of $72.73 \%$. The 13 patients with NSCLC had an ORR and DCR of 30.77 and $84.62 \%$, respectively. Furthermore, the 13 patients with SCLC had an ORR of $30.77 \%$ and a DCR of $53.85 \%$. The ORR of the patients with cervical cancer was $25 \%$ and the DCR was $75 \%$. Patients with esophageal cancerhad an
Table II. Toxicity and adverse effects ( $n=114$ cycles).

\begin{tabular}{lcccc}
\hline Grade & 1 & 2 & 3 & 4 \\
\hline Anemia & $23(20.2)$ & $4(3.5)$ & $1(0.9)$ & $1(0.9)$ \\
Leukopenia & $8(7.0)$ & $14(12.3)$ & $2(1.8)$ & - \\
Thrombocytopenia & $8(7.0)$ & $2(1.8)$ & $2(1.8)$ & $1(0.9)$ \\
Nausea & $3(2.6)$ & - & - & - \\
Fatigue & $6(5.3)$ & - & - & - \\
Hypertension & $20(17.5)$ & $6(5.3)$ & $5(4.4)$ & - \\
Proteinuria & $10(8.8)$ & $4(3.5)$ & $3(2.6)$ & - \\
Hand-foot syndrome & $8(7.0)$ & $3(2.6)$ & $2(1.8)$ & - \\
Hemorrhagic tendency & $2(1.8)$ & $1(0.9)$ & - & $2(1.8)$ \\
Bilirubin increased & $15(13.2)$ & $2(1.8)$ & - & - \\
Diarrhea & $7(6.1)$ & - & $2(1.8)$ & -
\end{tabular}

Values are presented as $\mathrm{n}(\%)$.

Table III. Analysis of safety in the cohort $(n=33)$.

\begin{tabular}{lcc}
\hline Adverse events & Any grade & Grade 3 or 4 \\
\hline Anemia & $16(48.5)$ & $2(6.1)$ \\
Leukopenia & $11(33.3)$ & $2(6.1)$ \\
Thrombocytopenia & $12(36.4)$ & $4(12.1)$ \\
Nausea & $4(12.1)$ & - \\
Fatigue & $4(12.1)$ & - \\
Hypertension & $17(51.5)$ & $5(15.2)$ \\
Proteinuria & $8(24.2)$ & $3(9.1)$ \\
Hand-foot syndrome & $10(30.3)$ & $1(3.0)$ \\
Hemorrhagic tendency & $6(18.2)$ & $2(6.1)$ \\
Bilirubin increased & $12(36.4)$ & - \\
Diarrhea & $4(12.1)$ & $1(3.0)$ \\
\hline Values are presented as $\mathrm{n}(\%)$. & & \\
\hline
\end{tabular}

ORR of $33.33 \%$ and a DCR of $100 \%$. However, for patients with advanced NSCLC and SCLC, there was nosignificant difference in DCR or ORR among the age groups,gender groups, KPS score groups and treatment cycle groups(Tables V and VI).The treatment efficacy for the 3 patients with cervical cancer and 4 patients with esophageal cancer is presented in Table VII.

For all patients receiving oral apatinib combined with S-1 therapy, the follow-up data suggested that the median PFS (mPFS) was 4.7 months and the median OS (mOS) was 10.8 months (Fig. 1). The mPFS of the 13 patients with SCLC was 3.3 months and the mOS was 11.6 months (Fig. 2). The mPFS of the 13 patients with NSCLC was 4.7 months and the mOS was 9.8 months (Fig. 3). There was no significant difference in the mPFS and mOS between the SCLC and NSCLC patients ( $\mathrm{P}=0.398$ and 0.87 , respectively) (Fig. 4). For the patients treated with radiotherapy during medication, the follow-up data suggested that the mPFS and mOS was 4.2 and 8.3 months, respectively (Fig. 5). Furthermore, 
Table IV. Association between clinical characteristics and adverse effects in patients with advanced solid tumor treated with apatinib plus $\mathrm{S}-1$.

\begin{tabular}{|c|c|c|c|c|c|}
\hline Clinical characteristic & $\mathrm{N}$ & Grade 1-2 adverse effects & Grade 3-4 adverse effects & $\chi^{2}$ & P-value \\
\hline Age (years) & & & & 2.695 & 0.101 \\
\hline$<60$ & 16 & $12(36.4)$ & $4(12.1)$ & & \\
\hline$\geq 60$ & 17 & $8(24.2)$ & $9(27.3)$ & & \\
\hline Sex & & & & 0.639 & 0.672 \\
\hline Male & 22 & $13(43.3)$ & $9(30.0)$ & & \\
\hline Female & 8 & $6(20.0)$ & $2(6.7)$ & & \\
\hline KPS scores & & & & 0.016 & 1.000 \\
\hline$<80$ & 25 & $15(45.5)$ & $10(30.3)$ & & \\
\hline$\geq 80$ & 8 & $5(15.2)$ & $3(9.1)$ & & \\
\hline Treatment cycles & & & & 0.002 & 1.000 \\
\hline$<3$ & 10 & $6(18.2)$ & $4(12.1)$ & & \\
\hline$\geq 3$ & 23 & $14(42.4)$ & $9(27.3)$ & & \\
\hline Cancer type & & & & 0.045 & 1.000 \\
\hline Respiratory system & 26 & $16(48.5)$ & $10(30.3)$ & & \\
\hline Non-respiratory system & 7 & $4(12.1)$ & $3(9.1)$ & & \\
\hline
\end{tabular}

Values are presented as $\mathrm{n}(\%)$.

Table V. Association between clinical characteristics and curative effect in patients with small-cell lung cancer treated with apatinib plus $\mathrm{S}-1$.

\begin{tabular}{|c|c|c|c|c|c|c|c|c|c|c|}
\hline Item & Total & PR & $\mathrm{SD}$ & PD & $\operatorname{DCR}(\%)$ & $\chi^{2}$ & P-value & ORR $(\%)$ & $\chi^{2}$ & P-value \\
\hline Age (years) & & & & & & 0.066 & 1.000 & & 0.034 & 1.000 \\
\hline$<60$ & 7 & 2 & 2 & 3 & 57.1 & & & 28.57 & & \\
\hline$\geq 60$ & 6 & 2 & 1 & 3 & 50 & & & 33.33 & & \\
\hline Sex & & & & & & 0.627 & 0.592 & & 3.611 & 0.105 \\
\hline Male & 8 & 4 & 1 & 3 & 62.5 & & & 50 & & \\
\hline Female & 5 & 0 & 2 & 3 & 40 & & & 0 & & \\
\hline KPS scores & & & & & & 6.964 & 0.021 & & 0.325 & 1.000 \\
\hline$<80$ & 8 & 2 & 0 & 6 & 25 & & & 25 & & \\
\hline$\geq 80$ & 5 & 2 & 3 & 0 & 100 & & & 40 & & \\
\hline Treatment cycles & & & & & & 1.040 & 0.559 & & 1.003 & 0.530 \\
\hline$<3$ & 9 & 2 & 2 & 5 & 44.4 & & & 22.22 & & \\
\hline$\geq 3$ & 4 & 2 & 1 & 1 & 75 & & & 50 & & \\
\hline
\end{tabular}

$\mathrm{CR}$, complete response; $\mathrm{PR}$, partial response; $\mathrm{PD}$ progressive disease; $\mathrm{SD}$, stable disease; $\mathrm{ORR}$, objective response rate; $\mathrm{DCR}$, the disease control rate.

the mPFS and mOS of the 4 patients with esophageal cancer was 9.2 and 12.9 months, respectively. The mPFS and mOS of the 3 patients with cervical cancer was 3.2 and 6.9 months, respectively (data not shown). In Fig. 6, a representative case of a patient with lung adenocarcinoma in whom a good effect was achieved is presented. After taking the medicine for 2, 4 and 6 cycles, the CT reexamination showed that the lesions were diminished than prior to taking the medicine and the tumor markers were also reduced.

\section{Discussion}

The present study was the first to evaluate the curative effect and safety of apatinib and S-1 in the treatment of refractory and recurrent solid tumors, to the best of our knowledge. The total DCR was $72.7 \%$ and the incidence rate of adverse effects (grade 3-4) was 45.5\%. The major side effects were hypertension, thrombocytopenia and proteinuria. In brief, apatinib combined with S-1 appeared to be effective and relatively safe 
Table VI. Association between clinical characteristics and curative effect in patients with non-small cell lung cancer treated with apatinib plus $\mathrm{S}-1$.

\begin{tabular}{|c|c|c|c|c|c|c|c|c|c|c|}
\hline Item & Total & PR & $\mathrm{SD}$ & PD & $\operatorname{DCR}(\%)$ & $\chi^{2}$ & P-value & ORR $(\%)$ & $\chi^{2}$ & P-value \\
\hline Age (years) & & & & & & 2.758 & 0.192 & & 0.034 & 1.000 \\
\hline$<60$ & 6 & 2 & 2 & 2 & 66.67 & & & 33.33 & & \\
\hline$\geq 60$ & 7 & 2 & 5 & 0 & 100 & & & 28.57 & & \\
\hline Sex & & & & & & 0.965 & 0.423 & & 1.733 & 0.497 \\
\hline Male & 10 & 4 & 5 & 1 & 90 & & & 40 & & \\
\hline Female & 3 & 0 & 2 & 1 & 66.67 & & & 0 & & \\
\hline KPS scores & & & & & & 0.197 & 1.000 & & 0.481 & 1.000 \\
\hline$<80$ & 12 & 4 & 6 & 2 & 83.33 & & & 33.33 & & \\
\hline$\geq 80$ & 1 & 0 & 1 & 0 & 100 & & & 0 & & \\
\hline Treatment cycles & & & & & & 2.758 & 0.192 & & 1.935 & 0.266 \\
\hline$<3$ & 6 & 3 & 1 & 2 & 66.67 & & & 50 & & \\
\hline$\geq 3$ & 7 & 1 & 6 & 0 & 100 & & & 14.29 & & \\
\hline Cancer type & & & & & & 0.014 & 1.000 & & 1.040 & 0.559 \\
\hline $\begin{array}{l}\text { Lung squamous-cell } \\
\text { carcinomas }\end{array}$ & 6 & 1 & 4 & 1 & 83.33 & & & 16.67 & & \\
\hline $\begin{array}{l}\text { Lung } \\
\text { adenocarcinoma }\end{array}$ & 7 & 3 & 3 & 1 & 85.71 & & & 42.86 & & \\
\hline
\end{tabular}

$\mathrm{CR}$, complete response; $\mathrm{PR}$, partial response; $\mathrm{PD}$, progressive disease; $\mathrm{SD}$, stable disease; $\mathrm{ORR}$, objective response rate; DCR, disease control rate.

Table VII. Curative effect in patients with advanced esophageal cancer and cervical cancer.

\begin{tabular}{lccccr}
\hline Cancer type & Total & PR & SD & PD & DCR (\%) \\
\hline Esophageal cancer & 4 & 1 & 2 & 1 & 75 \\
Cervical cancer & 3 & 1 & 2 & 0 & 100 \\
\hline
\end{tabular}

CR, complete response; $\mathrm{PR}$, partial response; $\mathrm{PD}$, progressive disease; $\mathrm{SD}$, stable disease; ORR, objective response rate; DCR, disease control rate.

in the treatment of solid tumor, but caution should be taken for patients with squamous-cell lung carcinoma.

Targeted therapy, immunotherapy, radiotherapy and chemotherapy are standard treatments for most types of carcinoma (23). A previous study indicated that the ORR and DCR was 42.2 and $51.5 \%$ in patients with NSCLC who received apatinib treatment (250 mg/day) (24). In comparison, the present study suggested that the ORR and DCR of the 13 patients with NSCLC were 30.77 and $84.62 \%$; for the 13 patients with SCLC, the ORR and DCR rates were 30.77 and $53.85 \%$, respectively. In the present study, the efficacy of apatinib combined with S-1 was confirmed and a significant antitumor effect was observed in patients with advanced lung cancer. However, the mPFS and $\mathrm{mOS}$ of the patients of the present study was only 3.3 and 11.6 months, respectively, which was considered similar to another study (25). As an example, in a single-center retrospective study, 23 cases of extensive-stage SCLC had received apatinib as maintenance therapy and the mPFS and mOS was 4.1 and 12.5 months, respectively (25). A major reason may be that the patients with SCLC in the present study who received multi-course treatment had a poor KPS score.

VEGF is highly expressed in numerous types of solid tumor (26), which has an important role in promoting endothelial cell survival and maintaining vascular integrity. Bleeding is a common adverse reaction of VEGFR inhibitor, which may be directly related to the inhibitory effect of the VEGF signaling pathway (27). Apatinib, targeting the VEGF signaling pathway, has been indicated to be a promising treatment for numerous types of cancer in preclinical and clinical trials (28). The majority of these patients $(n=24 ; 72.7 \%)$ exhibited tumor shrinkage or stabilization, which is better than the effect of other VEGFR-TKIs. The potential reasons may be as follows: i) When combined with chemotherapy, inhibition of VEGF may impair the ability of endothelial cells to repair or regenerate during tumor shrinkage, resulting in an increased risk of bleeding (29). As an example, the SD rate reported in a phase-I study of sorafenib for advanced refractory solid tumors was only $26 \%$ (30). In a pooled analysis of 137 patients with advanced refractory solid tumors in 4 phase-I 

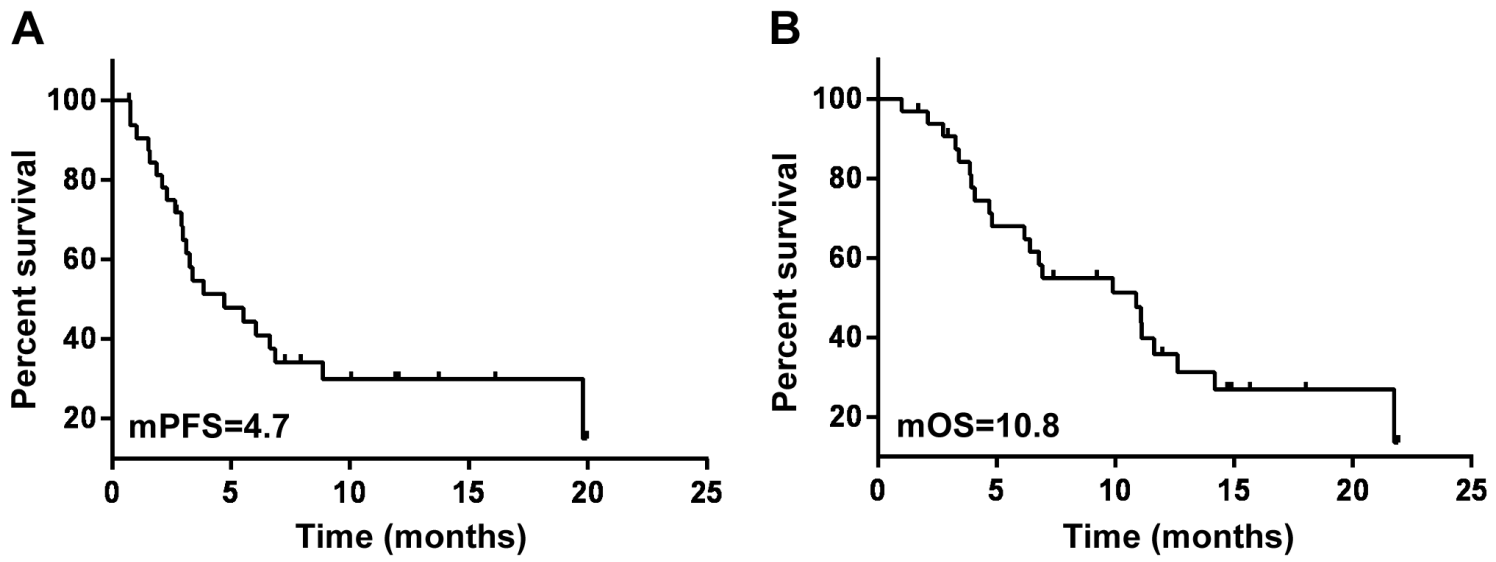

Figure 1. Kaplan-Meier analysis of all 33 patients with advanced solid tumor. (A) PFS (mPFS time, 4.7 months) and (B) OS (mOS time, 10.8 months). mPFS, median progression-free survival; mOS, median overall survival.
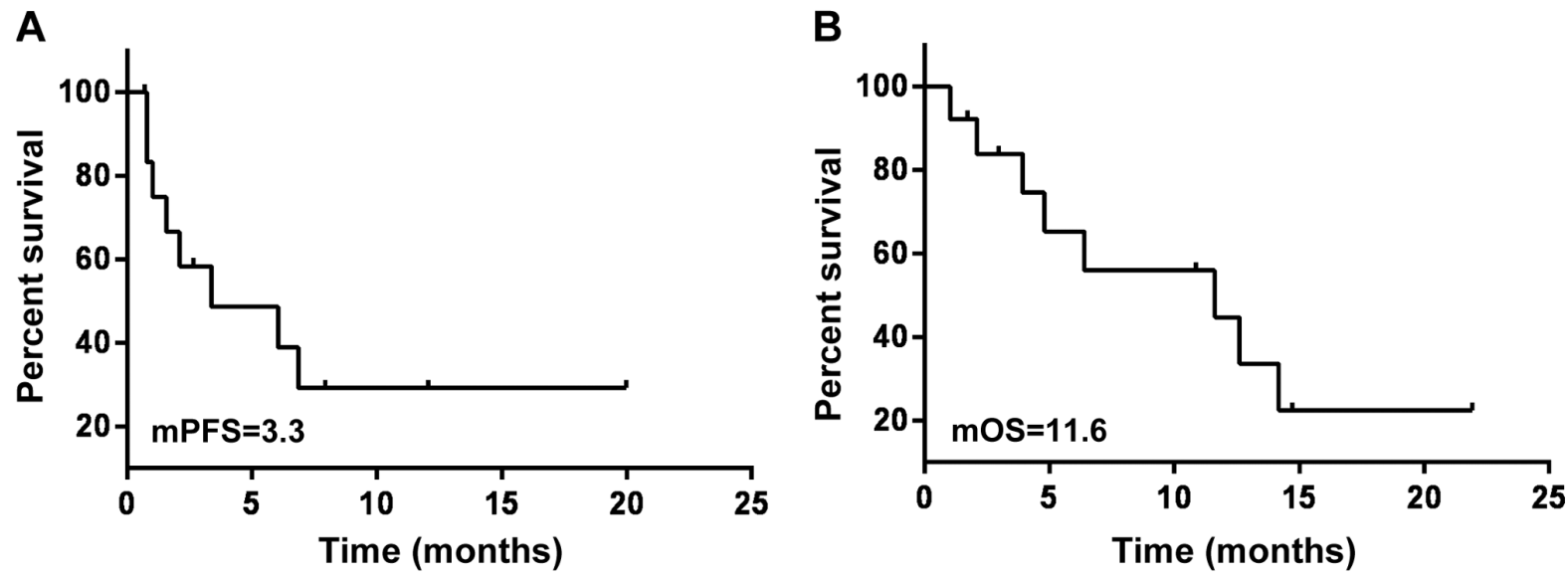

Figure 2. Kaplan-Meier analysis of 13 patients with advanced small-cell lung cancer. (A) PFS (mPFS time, 3.3 months) and (B) OS (mOS time, 11.6 months). mPFS, median progression-free survival; mOS, median overall survival.

A

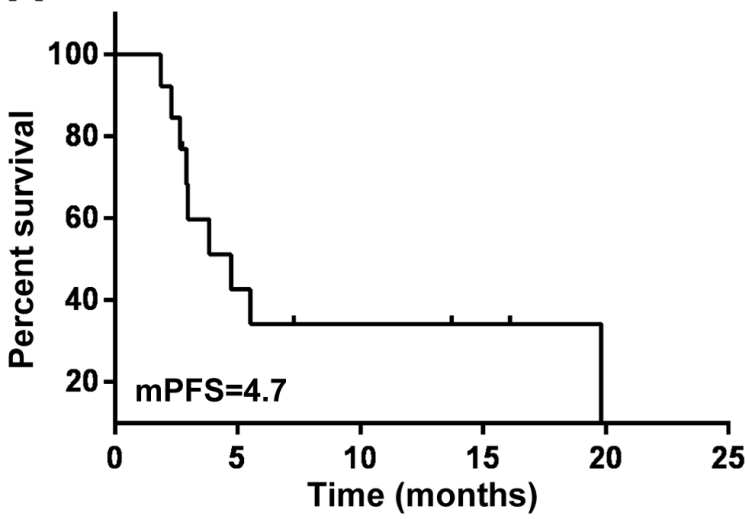

B

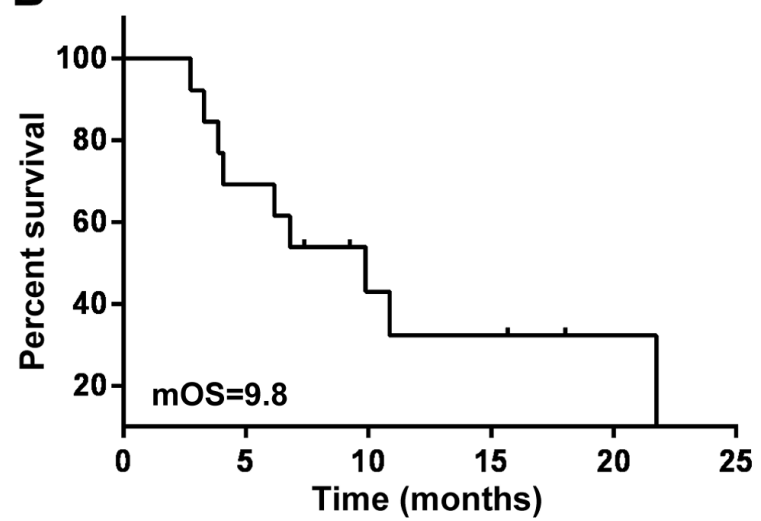

Figure 3. Kaplan-Meier analysis of 13 patients with advanced non-small-cell lung cancer. (A) PFS (mPFS time, 4.7 months) and (B) OS (mOS time, 9.8 months). mPFS, median progression-free survival; mOS, median overall survival.

trials of sorafenib, only 2 patients (1.4\%) achieved PR and $38(28 \%)$ achieved SD, while the majority of patients (70.8\%) exhibited PD on radiological imaging (31). ii) The combination treatment S-1 was proven effective in the treatment of certain types of solid cancer, including gastric (32), breast (33), colorectal (34) and pancreatic (35) cancer, and NSCLC (36). S-1 is a combination of the fluoropyrimidine-based anticancer agent tegafur (FT) as the effector drug with two modulators, 5-chloro-2,4-dihydroxypyridine (CDHP) and potassium oxonate (Oxo), at a molar ratio of 1:0.4:1 (37). The degradation of FT-derived 5-fluorouracil (5-FU) 
A

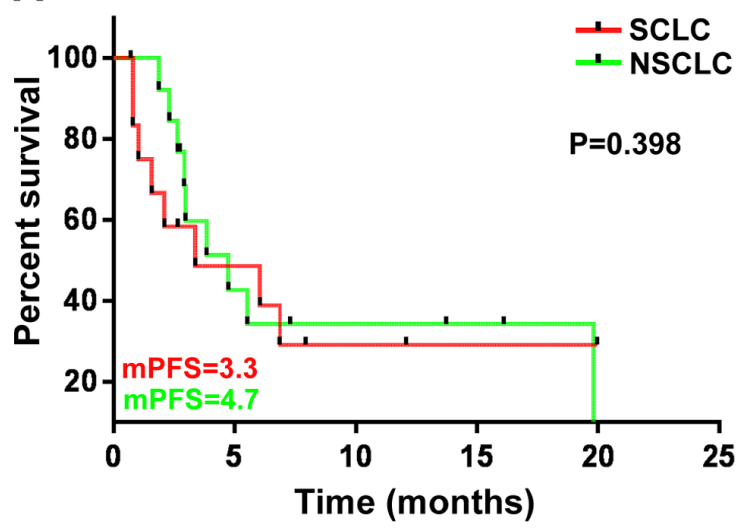

B

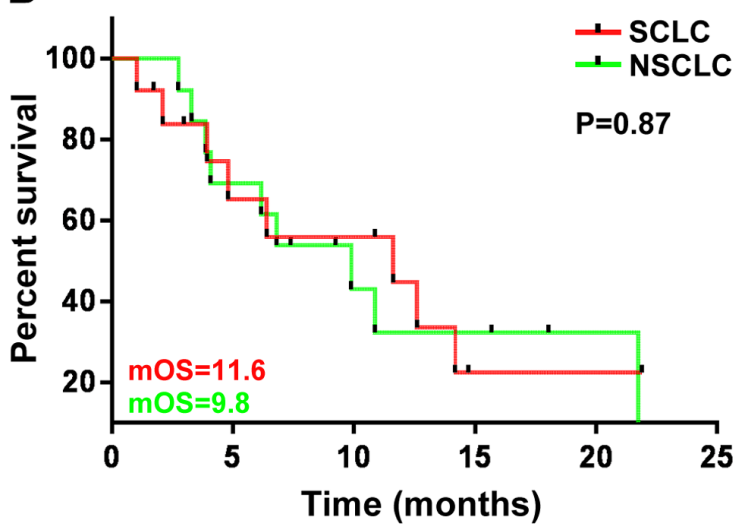

Figure 4. Kaplan-Meier analysis of patients with SCLC and NSCLC. There was no significant difference in (A) PFS (P=0.398) and (B) OS (P=0.870) between the two groups. NSCLC, non-small-cell lung cancer; mPFS, median progression-free survival; mOS, median overall survival.

A

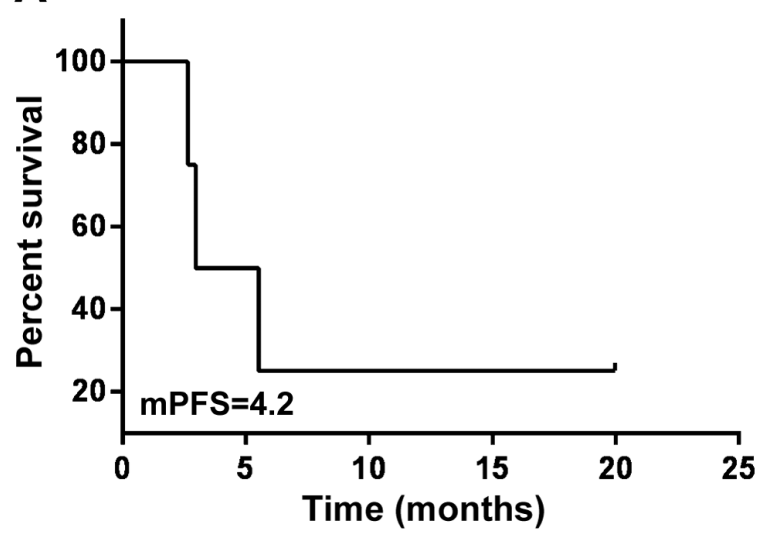

B

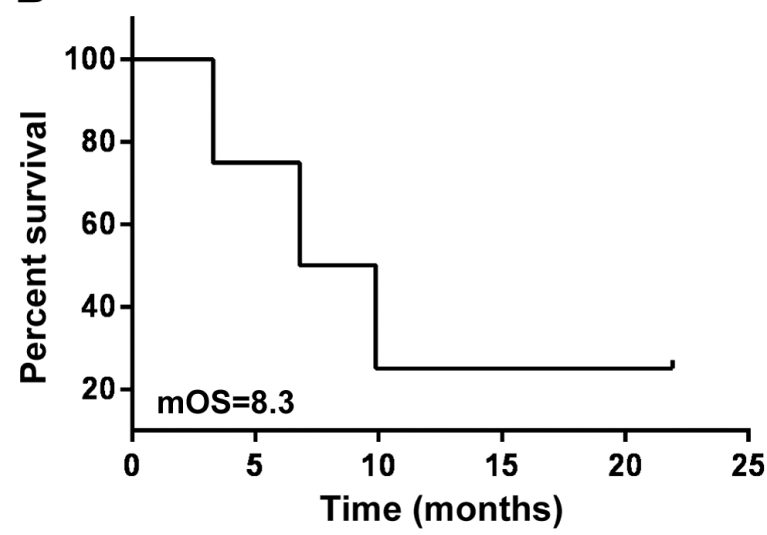

Figure 5. Kaplan-Meier analysis of 4 patients subjected to radiotherapy during medication. (A) PFS (mPFS time, 4.2 months) and (B) OS (mOS time, 8.3 months). mPFS, median progression-free survival; mOS, median overall survival.

A

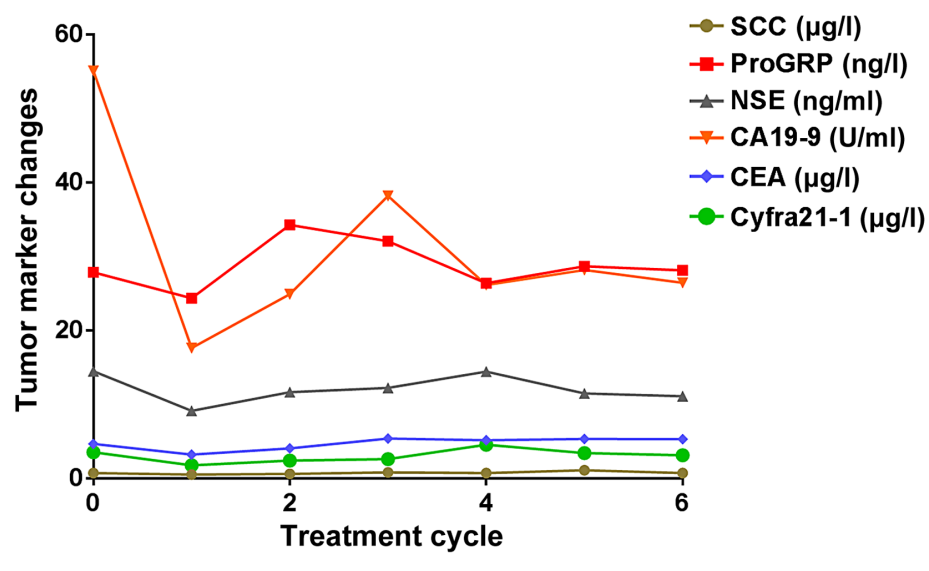

B

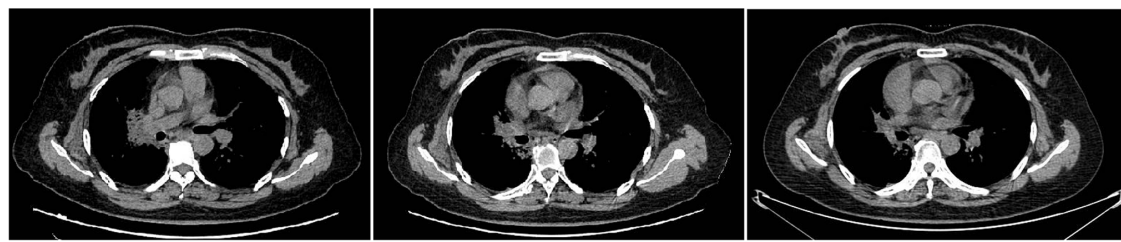

Figure 6. Follow-up data of a 60-year-old representative male patient with good efficacy. (A) Tumor markers were detected at the end of 0-6 cycles of treatment. (B) CT images were obtained prior to treatment and after 4 and 6 cycles of treatment (left to right). SCC, squamous cell carcinoma-related antigen; NSE, neurospecific enolase; CA19-9, carbohydrate antigen; CEA, carcinoembryonic antigen; Cyfra21-1, carbohydrate antigen; proGRP, pro-gastrin-releasing peptide. 
is inhibited by CDHP, resulting in enhancement of the antitumor effect $(38,39)$. Oxo reduces the gastrointestinal toxicity of 5-FU. After its oral administration, Oxo is distributed selectively to the small and large intestines, thereby reducing the incidence of diarrhea (40). A phase-II trial determined that the adverse event profile of the combination S-1 was neutropenia (10.3\%), leukopenia (13.8\%), anemia (3.4\%) and thrombocytopenia (3.4\%) (41).

In the present study, anemia, hypertension, leukopenia, increase of bilirubin, proteinuria and HFS were the most common treatment-associated toxicities. Among them, the incidence rate of grade 3-4 anemia, leukopenia and thrombocytopenia was only $6.1,6.1$ and $12.1 \%$, respectively. Most of the remaining adverse events were not severe and controllable (grade 1/2). These side effects may mainly be due to apatinib. While $69 \%$ of patients in the present study experienced myelosuppression, the cause of bone marrow suppression is the presence of VEGF receptors on bone marrow progenitor cells (42). Although $66.7 \%$ of the patients experienced hypertension, it was easy to lower blood pressure with medication. The key mechanism of hypertension is thought to be that VEGF inhibition diminishes nitric oxide synthesis and promotes vasoconstriction, thereby increasing peripheral resistance (43). Although $36.4 \%$ of patients experienced an increase of bilirubin, this was transient and disappeared gradually after the treatment was terminated. Furthermore, the incidence of HFS and proteinuria was low and of grade 1 or 2 in most cases. Of note, a patient with cervical cancer developed grade-3 HFS after taking two cycles of medication. A study has indicated that the mechanism is still unclear and may not be produced by blockade of the epidermal growth factor receptor, but rather by effects on intracellular downstream pathways (44). The use of lotions or moisturizers may help ease symptoms. In the present study, two patients died of massive hemorrhage, but neither of them had PD according to CT scan. This may be associated with the location of the lesion, which was close to the aorta in those patients. Therefore, apatinib should be used in patients with squamous-cell lung carcinoma with caution. Similar side effects have been reported for bevacizumab (avastin) and sunitinib malates (sutent, sorafenib and nexavar) (27,45-47). In the case of cough or high pressure in the thoracic region, massive hemoptysis due to the broken integrity of the vessel wall may be present. Thereby, the safety of apatinib in patients with advanced squamous-cell carcinoma may be worthy of recognition. The underlying mechanisms of treatment-associated pulmonary hemorrhage and its possible clinical risk factors should be further explored. It was indicated that squamous-cell histology, tumor erosion, necrosis or cavitation, tumor location close to major blood vessels or trachea may be considered as potential risk factors for apatinib-associated hemorrhage.

Of note, the present study had certain limitations. First, as it was an exploratory study, only a small number of patients were recruited without the availability of any better treatments, which may lead to unreliable statistical results. Furthermore, PFS and OS analysis were performed among different groups, but it may not be possible to generalize the conclusions from the subgroup analyses within the small heterogeneous cohort. It is necessary to perform further studies in the future.

In conclusion, the present study indicated that the combination of apatinib and S-1 had manageable toxicities and promising efficacy in patients with recurrent and refractory solid tumors, but the regimen should be used with caution in patients with squamous-cell lung carcinoma.

\section{Acknowledgements}

Not applicable.

\section{Funding}

This study was supported by a grant from the National Natural Science Foundation of China (grant no. 81372518 to PW) and the Tianjin Science and Technology Commission Project (grant no. 16JCYBJC25300 to NL).

\section{Availability of data and materials}

The datasets used and/or analyzed during the present study are available from the corresponding author on reasonable request.

\section{Authors' contributions}

SC, JS, HL, JL and DJ collected the clinical cases; SC performed statistical analysis; NL designed the study and obtained funding; SC drafted the manuscript; and LZ, YGS, YCS provided the cases and revised the manuscript. All authors read and approved the final manuscript.

\section{Ethics approval and consent to participate}

All procedures in studies involving human participants were performed in accordance with the ethical standards of the institutional research committee and with the 1964 Helsinki Declaration and its later amendments or comparable ethical standards. This study was approved by the Tianjin Medical University Cancer Institute and Hospital Human Research Ethics Committee (Tianjin, China). Comprehensive informed consent was obtained from all subjects.

\section{Patient consent for publication}

Not applicable.

\section{Competing interests}

The authors declare that they have no competing interests.

\section{References}

1. Chen W, Zheng R, Baade PD, Zhang S, Zeng H, Bray F, Jemal A, Yu XQ and He J: Cancer statistics in China, 2015. CA Cancer J Clin 66: 115-132, 2016.

2. van Hagen P, Hulshof MC, van Lanschot JJ, Steyerberg EW, van Berge Henegouwen MI, Wijnhoven BP, Richel DJ, Nieuwenhuijzen GA, Hospers GA, Bonenkamp JJ, et al: Preoperative chemoradiotherapy for esophageal or junctional cancer. N Engl J Med 366: 2074-2084, 2012.

3. Song Z, Yu X, Lou G, Shi X and Zhang Y: Salvage treatment with apatinib for advanced non-small-cell lung cancer. Onco Targets Ther 10: 1821-1825, 2017.

4. Carmeliet P and Jain RK: Angiogenesis in cancer and other diseases. Nature 407: 249-257, 2000

5. Roudsari LC and West JL: Studying the influence of angiogenesis in in vitro cancer model systems. Adv Drug Deliv Rev 97: 250-259, 2016.

6. Ferrara N, Gerber HP and LeCouter J: The biology of VEGF and its receptors. Nat Med 9: 669-676, 2003. 
7. Ebos JM, Bocci G, Man S, Thorpe PE, Hicklin DJ, Zhou D, Jia X and Kerbel RS: A naturally occurring soluble form of vascular endothelial growth factor receptor 2 detected in mouse and human plasma11ontario graduate scholarship in science and technology (J.M.L. Ebos); sunnybrook trust for medical research (G. Bocci); and NIH grant CA41223, Canadian institutes for health research, and national cancer institute of Canada (R.S. Kerbel). Mol Cancer Res 2: 315-326, 2004

8. Geng R, Song L, Li J and Zhao L: The safety of apatinib for the treatment of gastric cancer. Expert Opin Drug Saf 17: 1145-1150, 2018

9. Brower V: Apatinib in treatment of refractory gastric cancer. Lancet Oncol 17: e137, 2016.

10. Ding L, Li QJ, You KY, Jiang ZM and Yao HR: The use of apatinib in treating nonsmall-cell lung cancer: Case report and review of literature. Medicine (Baltimore) 95: e3598, 2016.

11. Li F, Liao Z, Zhao J, Zhao G, Li X, Du X, Yang Y and Yang J: Efficacy and safety of Apatinib in stage IV sarcomas: Experience of a major sarcoma center in China. Oncotarget 8: 64471-64480, 2017.

12. Scott A, Messersmith W and Jimeno A: Apatinib: A promising oral antiangiogenic agent in the treatment of multiple solid tumors. Drugs Today (Barc) 51: 223-229, 2015.

13. Li J, Qin S, Xu J, Xiong J, Wu C, Bai Y, Liu W, Tong J, Liu Y, $\mathrm{Xu} \mathrm{R}$, et al: Randomized, double-blind, placebo-controlled phase III trial of apatinib in patients with chemotherapy-refractory advanced or metastatic adenocarcinoma of the stomach or gastroesophageal junction. J Clin Oncol 34: 1448-1454, 2016.

14. Hu X, Zhang J, Xu B, Jiang Z, Ragaz J, Tong Z, Zhang Q, Wang X Feng J, Pang D, et al: Multicenter phase II study of apatinib, a novel VEGFR inhibitor in heavily pretreated patients with metastatic triple-negative breast cancer. Int J Cancer 135: 1961-1969, 2014.

15. Li J and Wang L: Efficacy and safety of apatinib treatment for advanced esophageal squamous cell carcinoma. Onco Targets Ther 10: 3965-3969, 2017

16. Li F, Zhu T, Cao B, Wang J and Liang L: Apatinib enhances antitumour activity of EGFR-TKIs in non-small cell lung cancer with EGFR-TKI resistance. Eur J Cancer 84: 184-192, 2017.

17. Hu X, Cao J, Hu W, Wu C, Pan Y, Cai L, Tong Z, Wang S, Li J, WangZ, et al:Multicenterphase II study of apatinibin non-triple-negative metastatic breast cancer. BMC Cancer 14: 820, 2014.

18. Shirasaka T, Nakano K, Takechi T, Satake H, Uchida J, Fujioka A, Saito H, Okabe H, Oyama K, Takeda S, et al: Antitumor activity of $1 \mathrm{M}$ tegafur-0.4 M 5-chloro-2,4-dihydroxypyridine-1 M potassium oxonate (S-1) against human colon carcinoma orthotopically implanted into nude rats. Cancer Res 56: 2602-2606, 1996.

19. Yumine K and Kawahara M: Phase II study of S-1, a novel oral fluorouracil, in advanced non-small-cell lung cancer. Gan To Kagaku Ryoho 33 (Suppl 1): 189-192, 2006 (In Japanese).

20. Zhang H, Xiong J, Guo L, Patel N and Guang X: Integrated traditional Chinese and western medicine modulator for overcoming the multidrug resistance with carbon nanotubes. RSC Adv 5 . 71287-71296, 2015.

21. Wu P, Li S and Zhang H: Design real-time reversal of tumor multidrug resistance cleverly with shortened carbon nanotubes. Drug Des Devel Ther 8: 2431-2438, 2014.

22. Mi YJ, Liang YJ, Huang HB, Zhao HY, Wu CP, Wang F, Tao LY, Zhang CZ, Dai CL, Tiwari AK, et al: Apatinib (YN968D1) reverses multidrug resistance by inhibiting the efflux function of multiple ATP-binding cassette transporters. Cancer Res 70 : 7981-7991, 2010

23. Gotwals P,Cameron S, Cipolletta D, Cremasco V,Crystal A,Hewes B Mueller B, Quaratino S, Sabatos-Peyton C, Petruzzelli L, et al: Prospects for combining targeted and conventional cancer therapy with immunotherapy. Nat Rev Cancer 17: 286-301, 2017

24. Wang SY, Liu Z, Ou W, Li N, Wu HQ, Mao XY and Yuan C: Apatinib monotherapy for advanced non-small cell lung cancer after the failure of chemotherapy or other targeted therapy. J Clin Oncol 35 (15 Suppl): e20626, 2017.

25. Yan X, Wang Q, Wang H, Li P, Zhang G, Zhang M, Zheng X, Yang J, Zhang X and Ma Z: Apatinib as maintenance therapy in extensive-stage small-cell lung cancer: Results from a single-center retrospective study. J Cancer Res Clin Oncol 145: 235-240, 2019

26. Roskoski R Jr: Vascular endothelial growth factor (VEGF) signaling in tumor progression. Crit Rev Oncol Hematol 62: $179-213,2007$

27. Kamba T and McDonald D: Mechanisms of adverse effects of anti-VEGF therapy for cancer. Br J Cancer 96: 1788-1795, 2007.

28. Scott LJ: Apatinib: A review in advanced gastric cancer and other advanced cancer. Drugs 78: 747-758, 2018

29. Kilickap S, Abali Hs and Celik I: Bevacizumab, bleeding, thrombosis, and warfarin. J Clin Oncol 21: 3542-3543, 2003
30. Clark JW, Eder JP, Ryan D, Lathia C and Lenz HJ: Safety and pharmacokinetics of the dual action Raf kinase and vascular endothelial growth factor receptor inhibitor, BAY 43-9006, in patients with advanced, refractory solid tumors. Clin Cancer Res 11: 5472-5480, 2005.

31. Strumberg D, Clark JW, Awada A, Moore MJ, Richly H, Hendlisz A, Hirte HW, Eder JP, Lenz HJ, Schwartz B, et al: Safety, pharmacokinetics, and preliminary antitumor activity of sorafenib: A review of four phase I trials in patients with advanced refractory solid tumors. Oncologist 12: 426-437, 2007.

32. Koizumi W, Narahara H, Hara T, Takagane A, Akiya T, Takagi M, Miyashita K, Nishizaki T, Kobayashi O, Takiyama W, et al: S-1 plus cisplatin versus S-1 alone for first-line treatment of advanced gastric cancer (SPIRITS trial): A phase III trial.Lancet Oncol 9: 215-221, 2008

33. Saeki T, Takashima S, Sano M, Horikoshi N, Miura S, Shimizu S, Morimoto K, Kimura M, Aoyama H, Ota J, et al: A phase II study of S-1 in patients with metastatic breast cancer-a Japanese trial by the $\mathrm{S}-1$ cooperative study group, breast cancer working group. Breast Cancer 11: 194-202, 2004.

34. Goto A, Yamada Y, Yasui H, Kato K, Hamaguchi T, Muro K, Shimada Y and Shirao K: Phase II study of combination therapy with S-1 and irinotecan in patients with advanced colorectal cancer. Ann Oncol 17: 968-973, 2006.

35. Okusaka T, Funakoshi A, Furuse J, Boku N, Yamao K, Ohkawa S and Saito H: A late phase II study of S-1 for metastatic pancreatic cancer. Cancer Chemother Pharmacol 61: 615-621, 2008.

36. Takakuwa O, Oguri T, Maeno K, Ozasa H, Iwashima Y, Miyazaki M, Kunii H, Takano Y, Mori T, Sato S and Ueda R: Efficacy of S-1 monotherapy for non-small cell lung cancer after the failure of two or more prior chemotherapy regimens. Oncol Lett 1: 147-150, 2010.

37. Shirasaka T, Shimamato Y, Ohshimo H, Yamaguchi M, Kato T, Yonekura K and Fukushima M: Development of a novel form of an oral 5-fluorouracil derivative (S-1) directed to the potentiation of the tumor selective cytotoxicity of 5-fluorouracil by two biochemical modulators. Anticancer Drugs 7: 548-557, 1996.

38. Tatsumi K, Fukushima M, Shirasaka T and Fujii S: Inhibitory effects of pyrimidine, barbituric acid and pyridine derivatives on 5-fluorouracil degradation in rat liver extracts. Jpn J Cancer Res 78: 748-755, 1987.

39. Oguri T, Achiwa H, Bessho Y, Muramatsu H, Maeda H, Niimi T, Sato S and Ueda R: The role of thymidylate synthase and dihydropyrimidine dehydrogenase in resistance to 5-fluorouracil in human lung cancer cells. Lung Cancer 49: 345-351, 2005.

40. Shirasaka T, Shimamoto Y and Fukushima M: Inhibition by oxonic acid of gastrointestinal toxicity of 5-fluorouracil without loss of its antitumor activity in rats. Cancer Res 53: 4004-4009, 1993.

41. Kaira K, Sunaga N, Yanagitani N, Imai H, Utsugi M, Iwasaki Y, Shimizu K, Iijima H, Tsurumaki H, Tomizawa Y, et al: Phase 2 study of S-1 plus carboplatin in patients with advanced non-small cell lung cancer. Lung Cancer 68: 253-257, 2010.

42. Hattori K, Heissig B, Wu Y, Dias S, Tejada R, Ferris B, Hicklin DJ, Zhu Z, Bohlen P, Witte L, et al: Placental growth factor reconstitutes hematopoiesis by recruiting VEGFR1(+) stem cells from bone-marrow microenvironment. Nat Med 8: 841-849, 2002.

43. Hood JD, Meininger CJ, Ziche M and Granger HJ: VEGF upregulates ecNOS message, protein, and NO production in human endothelial cells. Am J Physiol 274: H1054-H1058, 1998.

44. Alexandrescu D, Vaillant J and Dasanu C: Effect of treatment with a colloidal oatmeal lotion on the acneform eruption induced by epidermal grow th factor receptor and multiple tyrosine-kinase inhibitors. Clin Exp Dermatol 32: 71-74, 2007.

45. Johnson DH, Fehrenbacher L, Novotny WF, Herbst RS, Nemunaitis JJ, Jablons DM, Langer CJ, DeVore RF III, Gaudreault J, Damico LA, et al: Randomized phase II trial comparing bevacizumab plus carboplatin and paclitaxel with carboplatin and paclitaxel alone in previously untreated locally advanced or metastatic non-small-cell lung cancer. J Clin Oncol 22: 2184-2191, 2004.

46. Sandler A, Gray R, Perry MC, Brahmer J, Schiller JH, Dowlati A, Lilenbaum R and Johnson DH: Paclitaxel-carboplatin alone or with bevacizumab for non-small-cell lung cancer. N Engl J Med 355: 2542-2550, 2006.

47. Socinski MA, Novello S, Sanchez JM, Brahmer JA, Govindan R, Belani CP, Atkins JN, Gillenwater HH, Palleres C and Chao RC: Efficacy and safety of sunitinib in previously treated, advanced non-small cell lung cancer (NSCLC): Preliminary results of a multicenter phase II trial. J Clin Oncol 24 (18 Suppl): S7001, 2006.

This work is licensed under a Creative Commons

Attribution-NonCommercial-NoDerivatives 4.0 International (CC BY-NC-ND 4.0) License. 